\title{
A large, benign prostatic cyst presented with an extremely high serum prostate-specific antigen level
}

\author{
Han-Kuang Chen, Richard Pemberton
}

St John of God Subiaco Hospital, Subiaco, Western Australia, Australia

\section{Correspondence to} Dr Han-Kuang Chen, hankuang.chen@gmail.com

Accepted 21 December 2015

\section{SUMMARY}

We report a case of a patient who presented with an extremely high serum prostate specific antigen (PSA) level and underwent radical prostatectomy for presumed prostate cancer. Surprisingly, the whole mount prostatectomy specimen showed only small volume, organ-confined prostate adenocarcinoma and a large, benign intraprostatic cyst, which was thought to be responsible for the PSA elevation.

\section{BACKGROUND}

Many causes for elevation of serum prostate specific antigen (PSA) level have been described, such as prostate cancer, benign prostatic hyperplasia, prostatitis, digital rectal examination, prostate biopsy/resection, urinary retention and ejaculation. However, no published studies have linked the presence of benign prostatic cyst with elevation of PSA. In this case report, we describe a patient who presented with an extremely high PSA and whose whole mount prostatectomy specimen, surprisingly, showed only small volume, organ-confined tumours and a large, benign intraprostatic cyst. To our knowledge, this is the first reported case of a unilocular, non-haemorrhagic cyst causing marked PSA elevation.

\section{CASE PRESENTATION}

A 61-year-old man was referred by his general practitioner (GP), with an extremely high PSA level of $79 \mathrm{ng} / \mathrm{mL}$. This was on a background history of metastatic melanoma on the patient's lower back, which was treated with wide local excision and bilateral groin lymph node dissection 30 years prior. On rectal examination, there was a palpable and slightly tender cystic structure on the left side of the prostate. A CT scan of the abdomen and pelvis was performed, which showed a $23 \times 25 \times 17 \mathrm{~mm}$ cystic lesion within the prostate, which was thought to represent an abscess or haematoma (figure 1). The cystic lesion was then aspirated under sedation; the lesion contained only clear fluid. Microscopic examination of the cystic fluid found a moderate number of red blood cells and white cell counts, but there was no bacterial growth in the fluid culture. The patient had an uneventful recovery and was discharged on day 2 post procedure. Subsequently, this patient was lost to follow-up and did not have any more PSA tests carried out postoperatively. One year after the initial presentation, he was again referred by his GP to a different urologist, with a PSA level of $77 \mathrm{ng} /$ $\mathrm{mL}$.

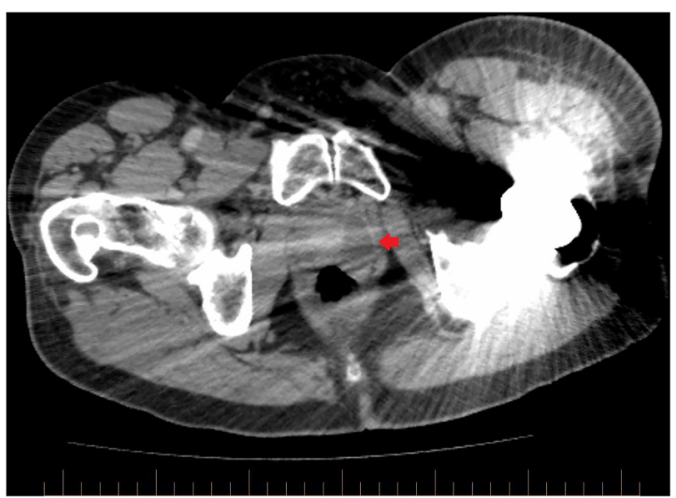

Figure 1 CT scan showing a $23 \times 25 \times 17 \mathrm{~mm}$ cystic lesion (red arrow) within the prostate, which was thought to represent an abscess or haematoma.

\section{INVESTIGATIONS}

The patient underwent a transrectal ultrasoundguided prostate biopsy and one core biopsy out of 12 showed Gleason $4+4$ adenocarcinoma with a mucinous component in the right mid region. Prostate volume was $38.2 \mathrm{cc}$ in ultrasound. An MRI scan of the prostate and pelvis was performed and again demonstrated a large peripheral zone prostatic cyst on the left (figure 2). In addition, the scan also showed suspicious lymphadenopathy in the right inguinal region up to $2 \mathrm{~cm}$ (figure 3 ). Given the patient's significant history of metastatic melanoma, a fluorodeoxyglucose positron emission tomography scan and fine needle aspiration of the right inguinal nodes were performed to guide

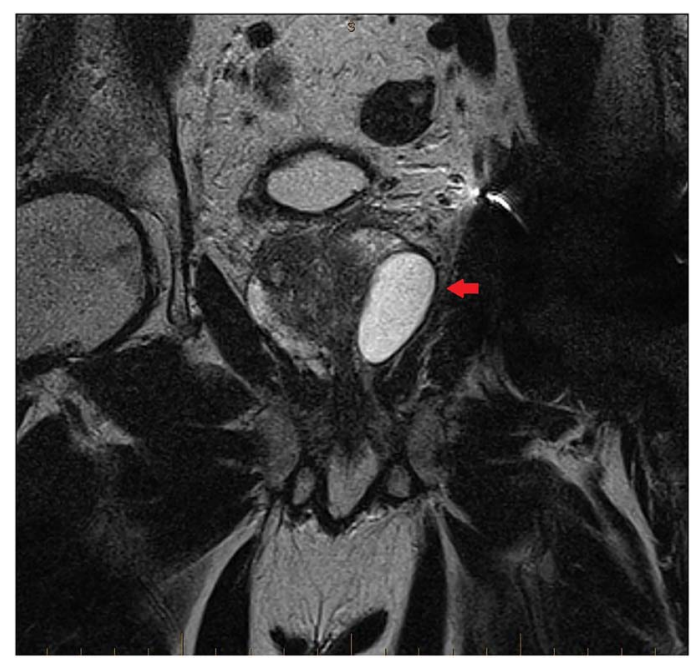

Figure 2 MRI of the prostate showing a residual large peripheral zone prostatic cyst on the left (red arrow). 


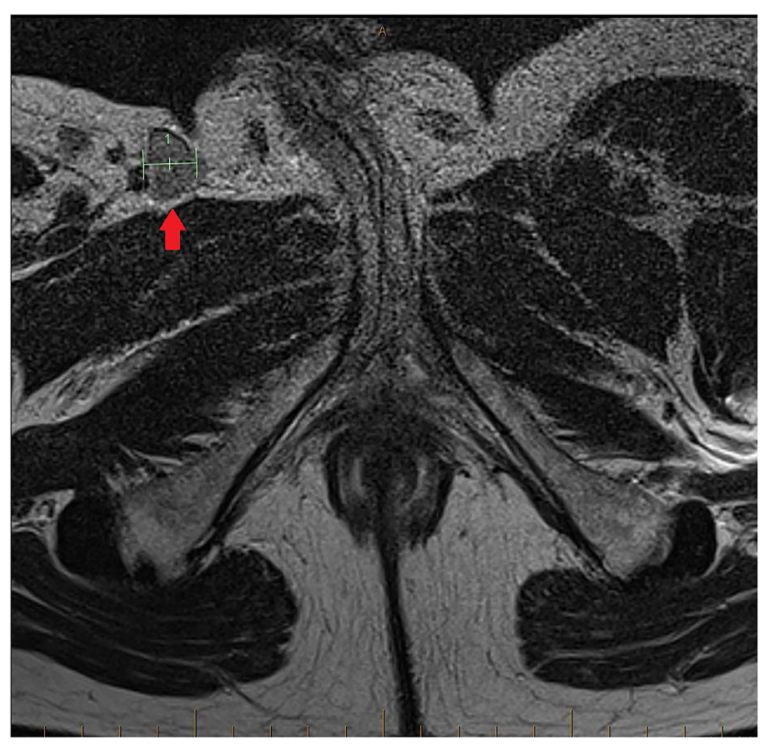

Figure 3 MRI scan of the prostate and pelvis showing suspicious lymphadenopathy in the right inguinal region (red arrow).

subsequent management. The results of both investigations showed no evidence of malignancy.

\section{DIFFERENTIAL DIAGNOSIS}

This case was discussed in multidisciplinary meetings with urological colleagues, oncologists and pathologists. The opinions were unanimous that this patient likely had prostatic adenocarcinoma requiring radical prostatectomy with pelvic lymph node dissection.

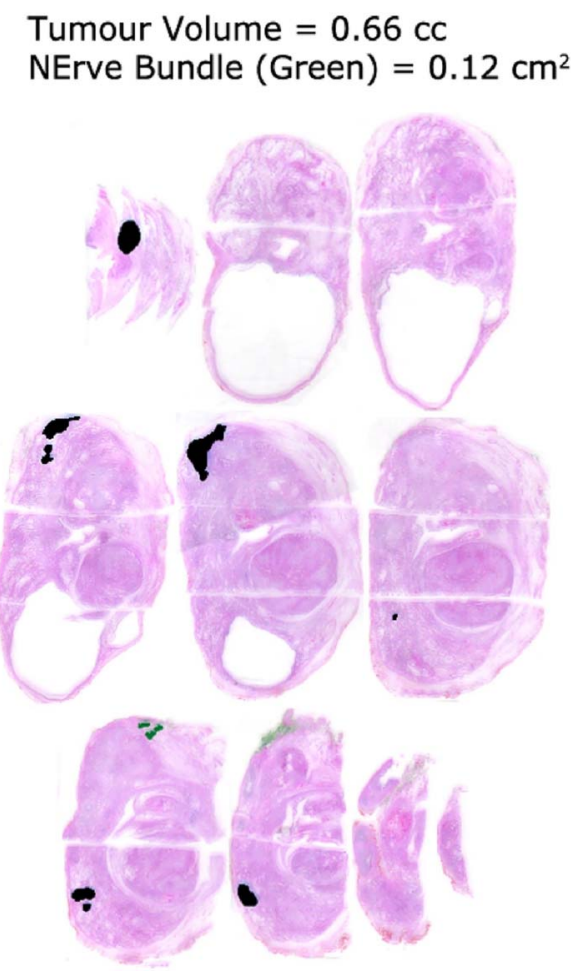

Figure 4 Whole mount prostatectomy specimen showing $0.66 \mathrm{cc}$ of tumour volume (black area) and a large intraprostatic cyst on the left.

\section{TREATMENT}

The patient underwent robot-assisted radical prostatectomy with pelvic lymph node dissection in September 2013.

\section{OUTCOME AND FOLLOW-UP}

The histopathology of the whole mount specimen, surprisingly, showed only $0.66 \mathrm{cc}$ of Gleason $4+3$ adenocarcinoma in bilateral peripheral zones, with a pathological stage of T2c (figure 4). The noteworthy feature was the presence of a large fibrous tissuelined prostatic cyst, which had replaced much of the left lobe volume. The prostate weighed $73 \mathrm{~g}$. The surgical margins were clear and all the lymph nodes showed reactive changes only.

Postoperative recovery was uneventful and the patient was discharged home on day 2. At 7 weeks post robot-assisted radical prostatectomy, the patient's PSA level was $0.03 \mathrm{ng} / \mathrm{mL}$. At 6 and 10 months follow-up, his PSA were undetectable at $<0.01 \mathrm{ng} / \mathrm{mL}$.

\section{DISCUSSION}

Given the serum PSA of $>10 \mathrm{ng} / \mathrm{mL}$, biopsy Gleason score of 8 and staging of T2c in this case, the updated Partin tables predict the most probable pathological stage being extraprostatic extension, followed by seminal vesicle and lymph node involvement. ${ }^{1}$ With a PSA level of $77 \mathrm{ng} / \mathrm{mL}$, one would logically expect a worse prognosis. Therefore, it was very unusual that the histopathology of the whole mount specimen showed an organconfined tumour. The small volume of the tumour also contradicted with the high PSA reading as preoperative PSA level is strongly associated with tumour volume in localised prostate cancer. $^{2}{ }^{3}$ If we use the equation developed by Kato et $a l^{3}$ to predict tumour volume in $\mathrm{cc}$ and the percentage of tumour volume in relation to the entire gland, we would expect $27.3 \mathrm{cc}$ of tumour volume occupying $66.9 \%$ of the entire prostate gland, given a PSA level of $77 \mathrm{ng} / \mathrm{mL}$. Therefore, the elevation of PSA level could not be attributed solely to prostate cancer in this case.

Apart from prostate cancer, many other causes for elevation of serum PSA have been described, such as benign prostatic hyperplasia, prostatitis, digital rectal examination, prostate biopsy/resection, urinary retention and ejaculation. ${ }^{4-7}$ However, the magnitude of PSA elevation caused by the factors above, in normal circumstances, would not be sufficient to achieve the serum PSA level seen in this case. There were also no features in this case suggesting that any of the above factors significantly interfered with the PSA measurements. The fact that serum PSA was elevated in presentations 1 year apart also indicated that the cause of the PSA elevation was not transient.

The question now is whether the benign prostatic cyst had played a role in PSA elevation. Prostatic cysts are common but they are usually diagnosed incidentally as most prostatic cysts are asymptomatic. ${ }^{8}$ Although prostatic cysts were not conventionally considered to influence serum PSA, the relationship between serum PSA level, and different types and sizes of cysts, has not been studied. ${ }^{8}$ Nonetheless, in multiple published case reports of benign prostatic cyst, high serum PSA level was observed. Seong et $a l^{9}$ reported a 43 -year-old man with multilocular cystic adenoma of the prostate who had a PSA level of $68.2 \mathrm{ng} / \mathrm{mL}$ on admission. Chakravarthy et $a l^{10}$ reported a 61 -year-old man who presented with a giant, $29 \times 22 \times 15 \mathrm{~cm}$, multilocular cystic adenoma of the prostate and his PSA level was $696 \mathrm{ng} / \mathrm{mL}$ on presentation. What our case had in common with the reported cases of multilocular prostatic cystadenoma were the benign nature of the cyst and highly elevated serum 
PSA level. However, the cystic lesion in our case was unilocular and it had no solid components in the cyst, as observed in these case reports. On the other hand, Chang et al ${ }^{11}$ reported a case of a 66-year-old man who had a serum PSA level of up to $44.2 \mathrm{ng} / \mathrm{mL}$ on admission and was diagnosed with only small foci of Gleason six prostate cancer and a benign haemorrhagic cyst. In this case report, however, they considered the probable cause of the PSA elevation to be haemorrhage of the prostate gland.

In the setting of a small volume, organ-confined tumour without other factors that may interfere with PSA measurement, we concluded that the large prostatic cyst in our case was responsible for the elevation of serum PSA level. To our knowledge, this is the first reported case of a unilocular, nonhaemorrhagic prostatic cyst causing marked elevation of serum PSA. More cases need to be studied to reliably determine the

\section{Learning points}

- Apart from prostate cancer, many other causes for elevation of serum prostate specific antigen (PSA) have been described, such as benign prostatic hyperplasia, prostatitis, digital rectal examination, prostate biopsy/resection, urinary retention and ejaculation.

- Prostatic cysts are common and are usually asymptomatic.

- Although prostatic cysts have not been conventionally considered to influence serum PSA, multiple cases of cyst related PSA elevation have been reported. In situations where PSA elevation is suspected to be cyst related, PSA analysis of the cystic fluid would be informative. relationship between prostatic cyst and serum PSA level. In situations where PSA elevation is suspected to be cyst related, we believe PSA analysis of the cystic fluid would provide useful information.

Contributors Both $\mathrm{H}-\mathrm{KC}$ and RP contributed to writing and revision of this article. Competing interests None declared.

Patient consent Obtained.

Provenance and peer review Not commissioned; externally peer reviewed.

\section{REFERENCES}

1 Eifler JB, Feng Z, Lin BM, et al. An updated prostate cancer staging nomogram (Partin tables) based on cases from 2006 to 2011. BJU Int 2013;111:22-9.

2 Carvalhal GF, Daudi SN, Kan D, et al. Correlation between serum prostate-specific antigen and cancer volume in prostate glands of different sizes. Urology 2010;76:1072-6.

3 Kato RB, Srougi V, Salvadori FA, et al. Pretreatment tumor volume estimation based on total serum psa in patients with localized prostate cancer. Clinics 2008;63:759-62.

4 Tchetgen MB, Oesterling JE. The effect of prostatitis, urinary retention, ejaculation, and ambulation on the serum prostate-specific antigen concentration. Urol Clin North Am 1997;24:283-91.

5 Chybowski F, Bergstralh E, Oesterling J. The effect of digital rectal examination on the serum prostate specific antigen concentration: results of a randomized study. J Urol 1992;148:83-6.

6 Herschman JD, Smith DS, Catalona WJ. Effect of ejaculation on serum total and free prostate-specific antigen concentrations. Urology 1997;50:239-43.

7 Kawakami J, Siemens DR, Nickel JC. Prostatitis and prostate cancer: implications for prostate cancer screening. Urology 2004;64:1075-80.

8 Galosi A, Montironi R, Fabiani A, et al. Cystic lesions of the prostate gland: an ultrasound classification with pathological correlation. J Urol 2009;181:647-57.

9 Seong BM, Cheon J, Lee JG, et al. A case of multilocular prostatic cystadenoma. J Korean Med Sci 1998;13:554-8.

10 Chakravarthy R, Sikand K, Ramani V, et al. Giant multilocular cystadenoma of the prostate-a potential pitfall on needle core biopsy. Int J Pathol 2008;8.

11 Chang Y, Chuang C, Ng K, et al. Coexistence of a hemorrhagic cyst and carcinoma in the prostate gland. Chang Gung Med J 2005;28:264-7.

Copyright 2016 BMJ Publishing Group. All rights reserved. For permission to reuse any of this content visit

http://group.bmj.com/group/rights-licensing/permissions.

BMJ Case Report Fellows may re-use this article for personal use and teaching without any further permission.

Become a Fellow of BMJ Case Reports today and you can:

- Submit as many cases as you like

- Enjoy fast sympathetic peer review and rapid publication of accepted articles

- Access all the published articles

- Re-use any of the published material for personal use and teaching without further permission

For information on Institutional Fellowships contact consortiasales@bmjgroup.com

Visit casereports.bmj.com for more articles like this and to become a Fellow 